Research Article

\title{
Water Inrush from Pregrouting Fractures Induced by Mining Activities and Its Engineering Control Method Optimization
}

\author{
Jianbo Li (i) \\ School of Safety Engineering, North China Institute of Science and Technology, Beijing 101601, China \\ Correspondence should be addressed to Jianbo Li; lijbo@126.com
}

Received 10 October 2018; Revised 25 December 2018; Accepted 3 April 2019; Published 7 May 2019

Academic Editor: Daniel W. M. Chan

Copyright (C) 2019 Jianbo Li. This is an open access article distributed under the Creative Commons Attribution License, which permits unrestricted use, distribution, and reproduction in any medium, provided the original work is properly cited.

\begin{abstract}
Water inrush accidents during coal mining still occur after reinforcement of fissured water bearing strata underlying coal seams through grouting, which seriously troubles field technicians. In order to further prevent the water inrush, especially the water inrush after grouting reinforcement, the grouting technique needs to be improved. Experimental design, theoretical analysis, and numerical simulation have been carried out in sequence. On the microscale level, the relationship between strains and water flow rate was analyzed through laboratory experiments; on the macroscale level, the propagation mechanism of grouting cracks resulting from the rock strata deformation during coal production was analyzed with rock beam theory, and then a new model of casing pipes preventing water inrush by controlling deformation of the floor rock strata is proposed. The laboratory test results show that the response of the radial strain and the water flow rate to mining operation is consistent and positively correlated and verify that it is feasible to reduce water inrush disaster by controlling deformation of the rock strata. The deformation governing equation of the casing pipes is deduced theoretically. At last, the numerical calculation was done to prove the effectiveness of controlling the floor rock strata deformation by the casing pipe group, which indicated that the displacement of the monitoring points after grouting is smaller than that before grouting practice. It is practicable to realize grouting technique optimization by the innovative adoption of the grouting casing pipes in the future.
\end{abstract}

\section{Introduction and Background}

Coal is still of crucial significance for the economic development in domestic China. However, lots of coal mines in China are suffering various groundwater disasters during coal production [1], which is prone to be worse at greater mining depths due to the influence of high ground stress and high water pressure [2].

Generally, there are mainly three key scientific issues concerning underground water threat during coal production, including the mechanism of water inrush [3-5], the prevention approaches of water inrush [6,7], and the evaluation of grouting effect [8]. Specifically, there are many factors affecting water inrush such as formation pressure, productivity, geologic structures, and the water pressure in the confined aquifer, though the declining of constraints due to mining is the major cause of the water-conducting failure of the floor rock strata in the coal seams [3]. Indeed, the cracks filled with slurry have high strength under confining pressure to prevent water inrush [9]. Furthermore, in aspects of engineering deployment and effectiveness evaluation, the grouting practice results for a section of the APSE tunnel were analyzed [7] and the rock mass improvement due to cement grouting by Q-system at Bakhtiari dam site was evaluated [8]. Although there are three key scientific problems for scientific researchers, it is as a matter of fact that only one intractable and practical engineering problem as to a single coal mine, that is, to prevent water inrush to ensure operation safety. At present, the most commonly used effective method to prevent water inrush from the confined aquifers in coal seam floor is adopting grouting practice for the large groundwater flow mines mainly based on the theory of slurry diffusion radius [10]. In this paper, the engineering control of water inrush refers to grouting practice.

Indeed, it is very difficult to establish a unified theoretical criterion to guide the grouting practice, as the geologic 
conditions between different mining areas are varied. Aiming to clarify and smoothly solve the issues, a typical mine with a long history of investigation in Zhaogu mining area of China is selected. The water pressure of the Ordovician limestone aquifers in this area is up to $6 \mathrm{MPa}$, which makes mining operations dangerous and intractable. Over years, more than 70 accidents with water bursting volume greater than $600 \mathrm{~m}^{3} / \mathrm{h}$ have been reported, which caused huge economic losses and interfered the routine production. The advanced grouting system still have to be deployed, though the operating costs of coal mine amount to be rather high, because adequate measures, regardless of costs, need to be implemented to ensure safety of mining operations. Under such circumstances, a new grouting method before mining is established in Zhaogu No. 2 coal mine, including five parts: dispersed pulping, capillary slurry transport, using three-level casing pipes with different diameters fixed together to prevent slurry spraying, multiple penetration and grouting, and complete coverage of grouting [11]. However, water inrush still occurs in some mining areas after grouting during production, such as Zhaogu I, Guhanshan, Jiulishan, Yanmazhuang coal mines, etc., which makes mine workers very puzzled.

Indeed, there are many literature statements about grouting, including grout diffusion radius, grout composition and grouting materials. Grouting technique and instruments have made great progress with the advancement of science and technology. But it is not enough to solve the problem of water inrush induced by pregrouting fractures during coal production in this paper. As a result, a new approach of controlling propagation of grouting cracks to prevent water inrush by grouting casing pipes needs to be proposed. In this paper, the test is firstly designed to clarify the mechanism of water inrush induced by the pregrouting fractures penetrated by confined water during coal production. Then, the in-site propagation mechanism of the cracks filled with cement slurry is theoretically analyzed. Finally, the method of preventing water inrush by grouting casing pipes through controlling grouting cracks propagation is proposed.

\section{Test on Pregrouting Fractures Penetrated by Confined Water during Mining Operations}

2.1. Theoretical Analysis of Failure Mechanism. In the test, the ratio of confining pressure to axial pressure is selected to illustrate the effect of confining pressure on failure. When the confining pressure is greater than the axial pressure, the vertical fissure will be pressed and closed, and the radial strain will not increase. On the contrary, when the confining pressure is less than the axial pressure, the vertical fissure will be expanded and the radial strain will increase.

Here, Mohr-Coulomb theory is used to analyze the failure problem. As shown in Figure 1, the rock sample contains a through-fracture, where the minimum principal stress is $\sigma_{3}$, the maximum principal stress is $\sigma_{1}$, the inclination angle of the through-fracture is $\beta$, the cohesion of the interface is $c_{\mathrm{f}}$, the internal friction angle is $\varphi_{\mathrm{f}}$, and the

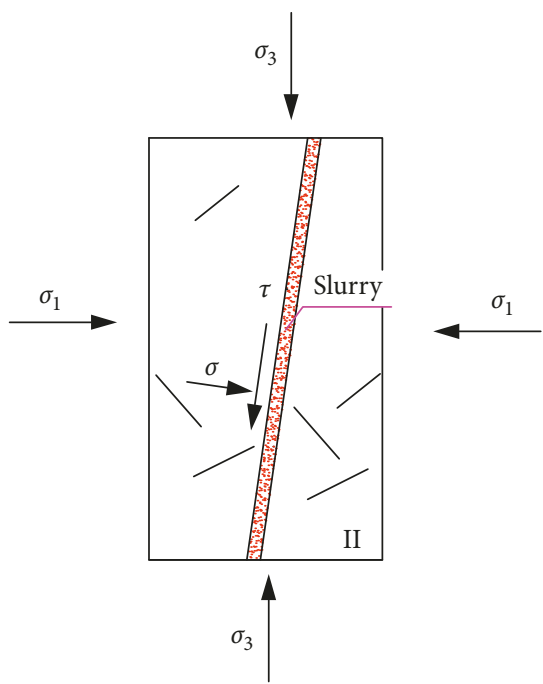

FIgURE 1: Model of fracture filled with cement slurry through the rock sample vertically.

shear stress and the normal stress on the fracture surface are $\tau$ and $\sigma$, respectively.

The fracture strength obeys the Mohr-Coulomb failure criterion, the equation is $\tau=c_{\mathrm{w}}+\sigma \tan \varphi_{\mathrm{w}}$, and another form expressed with $\sigma_{1}$ and $\sigma_{3}[12]$ is as follows:

$$
\sigma_{1}=\sigma_{3}+\frac{2\left(c_{\mathrm{w}}+\sigma_{3} \tan \varphi_{\mathrm{w}}\right)}{\left(1-\tan \varphi_{\mathrm{w}} \cot \beta\right) \sin (2 \beta)} .
$$

When $\sigma_{3}=0$, the cracks filled with cement slurry are subjected to force in only one direction, and the critical failure strength is

$$
\sigma_{\mathrm{f} 1}=\frac{2 c_{\mathrm{f}}}{\left(1-\tan \varphi_{\mathrm{f}} \cot \beta\right) \sin (2 \beta)} .
$$

When $\sigma_{1}=0$, the critical failure strength of the cracks filled with cement slurry is

$$
\sigma_{\mathrm{f} 3}=\frac{-2 c_{\mathrm{f}}}{\left(1-\tan \varphi_{\mathrm{f}} \cot \beta\right) \sin (2 \beta)+2 \tan \varphi_{\mathrm{f}}} .
$$

The strength of the interface between the cement slurry and rock is small. When stress is greater than $\sigma_{\mathrm{f} 1}$ or $\sigma_{\mathrm{f} 3}$ under the corresponding unidirectional stress state, the interface between cement slurry and rock in the fracture is destroyed, which is consistent with what is observed in the experiment.

Overall, the strength of the interface between cement slurry and rock is less than that of the rock itself and also less than the strength of the solidified grout cement. It is the weakest and most easily destroyed place in the reinforced rock masses. Stress relief is very important for crack propagation, and a through fracture is an important condition for water inrush.

2.2. Basic Problems and Instruments. Many simulation experiments have been done for water inrush originated from the confined aquifers under coal production, and many useful experimental phenomena and laws of water inrush have been discovered and interpreted [13, 14]. Generally 
speaking, the design of water inrush experiment requires three aspects: material simulation, in situ stress simulation, and hydraulic simulation. Correspondingly, there are three problems: (a) sealing and exerting high water pressure are very difficult; (b) it is difficult to determine similar materials due to the uncertainty of similarity ratio; (c) how to simulate mining operations after sealing. In view of these reasons, this paper chooses a three-axial test machine (Figure 2). On the one hand, the machine can apply axial stress, confining pressure and high water pressure the experiment needs; on the other hand, the machine can gradually reduce confining pressure.

2.3. Geologic and Stress Conditions. Water inrush is affected by geologic conditions, hydrogeological conditions, and grouting effect. A single working face in Zhaogu No. 1 coal mine is selected to be investigated, and its spatial forms of the working face and in situ stress conditions are shown in Figure 3.

The burial depth of this working face is about $700 \mathrm{~m}$. Coal seam thickness $T$ is about $6 \mathrm{~m}$ and the length of working face $(L)$ in the dip direction is about $180 \mathrm{~m}$. In the local coordinate system (xoy), two stresses, $\sigma_{1}$ and $\sigma_{2}$, have their respective components in $x$ and $y$ directions, and these stress components play an important role in crack propagation and the deformation and failure of rock strata. According to the research results of an adjacent mine [15], the average maximum principal stress $\sigma_{1}$ of the studied area is $28.51 \mathrm{MPa}$, the average intermediate (vertical) principal stress $\sigma_{2}$ is $16.44 \mathrm{MPa}$, and the average minimum principal stress $\sigma_{3}$ is $15.04 \mathrm{MPa}$. During the test, confining pressure is set to be equal in radial direction, and mining operations is simulated by unloading confining pressure, which is the direct inducement of the water inrush accidents [3].

2.4. Preparation of Experimental Materials. Test materials are obtained by drilling. The rock pillars with diameter of $50 \mathrm{~mm}$ and height of $100 \mathrm{~mm}$ are prepared in sequence by the coring machine, cutting machine, and grinding machine. Firstly, these rock samples were fractured by the test machine. Secondly, select the rock pillars with different fracture forms. (In fact, these broken rock samples can be selected after the strength tests as the pregrouting broken rock samples. In this way, it is not necessary to specialize in making fractured rock samples so as to kill two birds with one stone.) Thirdly, improve the selected fractured rock samples by slurry.

Three kinds of rock samples with different fracture distributions are designed and selected (Figure 4), and the rock samples before and after grouting are selected and shown in Figure 5.

2.5. Experimental Procedure. Experimental materials and boundary conditions have been determined. Initiate the test. At the beginning, the axial stress is set to $18 \mathrm{MPa}$, the confining pressure is set to $25 \mathrm{MPa}$, and the water pressure is set to $6 \mathrm{MPa}$. Then, keep axial load constant and reduce



FiguRE 2: Explanatory sketch of the mechanical test system.

confining pressure gradually. Parameters such as confining pressure, water pressure, water flow rate, and strains are monitored throughout the test. The stress state of pregrouting rock pillars in the pressure chamber is shown in Figure 6.

2.6. Variation of the Water Flow Rate according to Different Fracture Patterns. Three rock samples with different fracture patterns were tested, respectively. The water flow rate changes of three rock samples with different fracture distributions are recorded over time, and their curve changes are shown in Figure 7. Obviously, the water flow rate of type III fractured rock sample linearly increased very slowly from the beginning to the end, while the water flow rate of type I and type II samples increased significantly, especially after 23 minutes. There is a fracture through the bottom to the top in both type I and type II rock samples, but no such fissures in type III rock sample is observed. The test demonstrates that the grouting rock samples with vertical fractures through the rock pillar are easier to be penetrated by high pressure water when disturbed by mining activities rather than generating some new fractures.

\subsection{Relationship between Water Flow Rate and Radial Strain.} Two parameters, water flow rate and radial strain, are recorded and their curves with different confining pressure are plotted together. The curve changes of two quantities of type I grouting rock sample are shown in Figure 8.

The process of confining pressure decline is divided into three stages (Figure 8). In the first stage (from $25 \mathrm{MPa}$ to $17 \mathrm{MPa}$ ), strains and water pressure values do not increase as the confining pressure is lowed. In stage II (from $17 \mathrm{MPa}$ to 


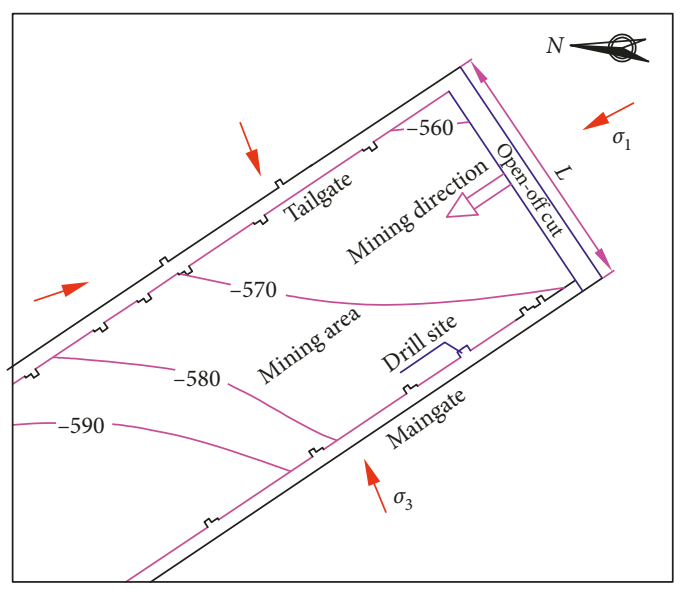

(a)

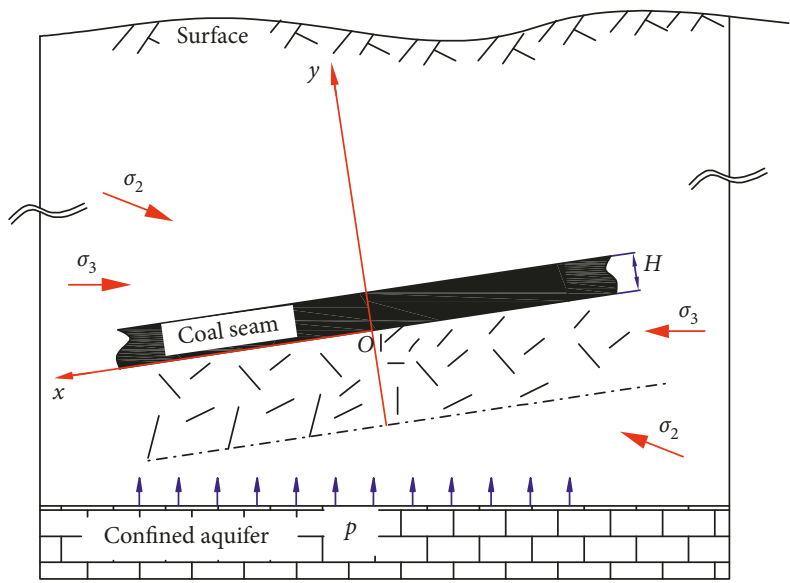

(b)

FIgURE 3: Spatial form of a working face and in situ stress conditions on a (a) plan view and (b) sectional view.

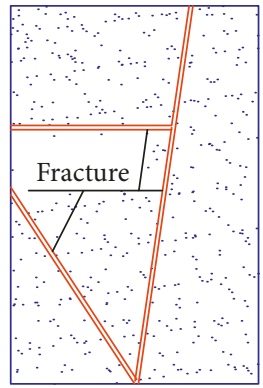

(a)



(b)

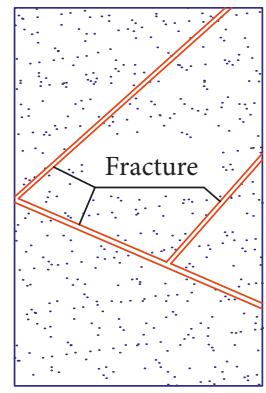

(c)

FIGURE 4: Sketch map of three rock samples with different fracture distributions: (a) I; (b) II; (c) III.

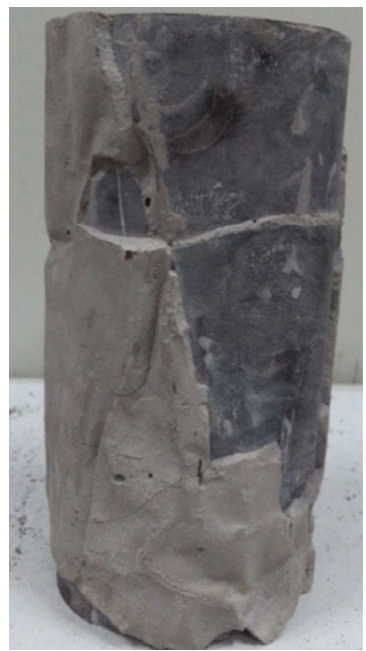

(a)

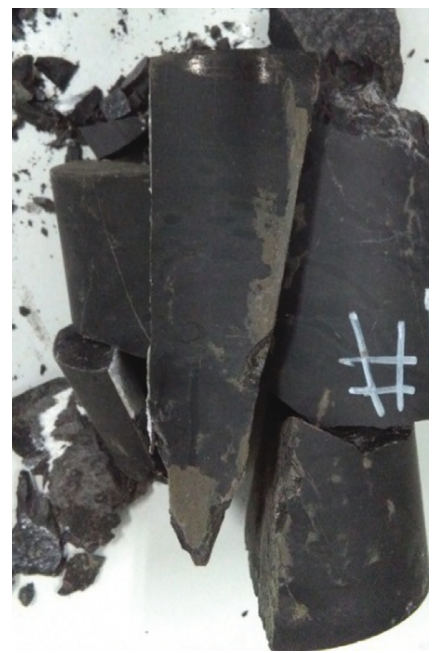

(b)

Figure 5: Photos of rock samples (a) after grouting and (b) before grouting.

$7 \mathrm{MPa}$ ), strain curves become fluctuating, sensitive, and unstable, while there is only a linear increase in water inflow curve. In the third stage, the confining pressure values are less than $7 \mathrm{MPa}$, the water flow rate curve has a large jump, and the radial strain curve also has two sharp increases, which shows that the feedback of these two variables to mining operations is consistent and positively correlated. More specifically, when the confining pressure is reduced 


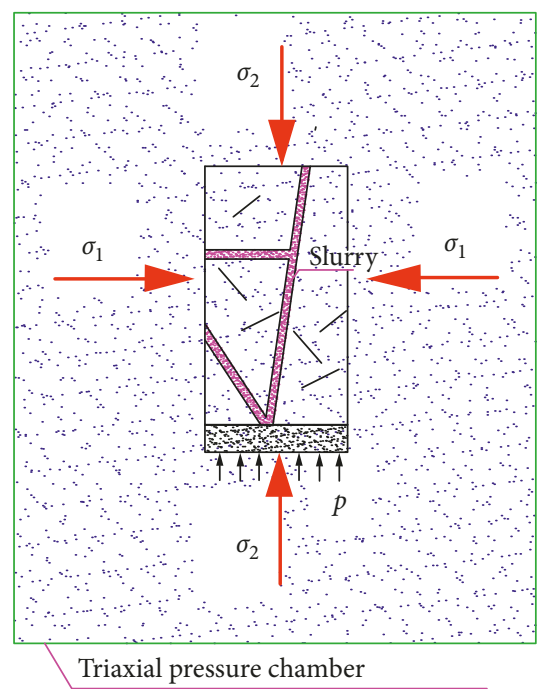

FIGURE 6: Stress state of pregrouting rock pillars in the pressure chamber.

from 25 to $7 \mathrm{MPa}$ (Figure 8), radial strain curve presented an undulation change and water flow rate is increased steadily by $5.7 \%$ from $1523 \mathrm{ml}$ to $1610 \mathrm{ml}$. When the confining pressure is reduced to less than $7 \mathrm{MPa}$, the water flow rate is increased by $10.6 \%$ from $1610 \mathrm{ml}$ to $1780 \mathrm{ml}$, and the radial strain is increased sharply by 16.2 times, from 0.01 to 0.172 .

\section{Propagation of Grouting Cracks during Mining Operations in a Real Coal Mine}

There are many research ideas to solve floor deformation and even failure, such as voussoir beam and key rock stratum [16]. These mechanical models are usually based on elastic thin plate theory or beam theory of mechanics of materials.

In this paper, rock beam theory is selected to analyze rock strata deformation during coal production at the time of initial roof weighting. According to the geologic conditions of the studied area, the sketch map of strata, in situ stress, and water pressure is finished. The model of a rock beam with a unit width and $h$ thickness before and after mining is shown in Figure 9.

The strata are arranged sequentially before mining. After coal goaf area reaches a certain size, the floor rock strata under the coal seam are deformed, following by fractures propagation and failure.

The bending moment $M$ and the inner stress of rock beam can be derived according to the given boundary conditions. Under the joint action of in situ stresses and water pressure, the rock beam is deformed by the action of bending moment $M$, and the internal stress satisfies the conditions in the $x^{\prime}$ o $y^{\prime}$ coordinate system (Figure 9):

$$
\sigma=\left(\frac{E}{\rho}\right) y^{\prime}=\left(\frac{M}{I_{z}}\right) y^{\prime}
$$

where $I_{z}$ is the aerial moment of inertia, $E$ is the modulus of elasticity, and $\rho$ is the radius of curvature after deformation of the neutral layer.
The stress directions of the upper and lower strata of the beam are opposite. Generally, the upper stratum of the beam is subjected to tensile stress $\left(y^{\prime}>0\right)$, while the lower stratum is subjected to compressive stress $\left(y^{\prime}<0\right)$. So, when the internal stress $\sigma$ is greater than the critical uniaxial strength of grouting cracks, the fracture is expanded and destroyed.

\section{Mechanism of Preventing Water Inrush by Grouting Casing Pipes}

Macroscopic deformation and microscopic strain are essentially consistent. Deformation of floor rock strata has great influence on crack propagation, especially vertical fractures (Radial strain is usually used to measure vertical fractures in rock test).

Grouting casing pipes can be used to prevent floor stratum deformation. It has been proved that the strength of steel pipes after being grouted with cement slurry can be greatly improved and have been widely used in roadway support, tunnel excavation, and other civil engineering fields $[17,18]$. The schematic diagram of grouting casing pipes layout at a working face in Zhaogu No. 2 coal mine is shown in Figure 10(a).

Select a casing pipe for analysis. A simplified action model of the casing pipe is established (Figure 10(b)). The casing pipe is divided into two parts. One part is in intact rock area, with relatively stable stress conditions, and regarded as a fixed end; the other part is located in disturbed rock stratum, and it is just this part infilled with slurry that prevents rock stratum deformation by its own bending resistance. Overall, the part in the disturbed area moves upward to prevent floor rock stratum deformation.

The equation of relationship between $M$ and $\sigma$ can be derived, as shown in Figure 10(b). The casing pipe is divided into two parts at point $N$, the disturbed part $l_{\mathrm{d}}$ and the other part in the intact zone $l_{\mathrm{o}}$.

A differential element with a width of $d r$ is taken at point $(x, y)$. Normal stress is distributed on the differential element section of the casing pipe, and the normal stress of the casing pipe at this point is $\sigma_{\alpha}(x, y)$. The bending moment $d M_{\alpha}$ generated by the normal stress in the differential unit at point $N$ is

$d M_{\alpha}(x, y)=\sigma_{\alpha}(x, y) d\left[l_{d}-r\right] d r$, where $d$ is the diameter of the casing pipe and $r=|y / \sin \alpha|$.

So, the total bending moment $M_{\alpha}$ at point $N$ caused by the normal stress acting on $l_{\mathrm{d}}$ part is

$$
M_{\alpha}(x, y)=\int_{0}^{l_{\mathrm{d}}} \sigma_{\alpha}(x, y) d\left[l_{\mathrm{d}}-r\right] d r .
$$

The relationship between normal stress and bending moment under bending condition is

$$
\sigma=\left(\frac{E}{\rho}\right) y^{\prime}=\left(\frac{M}{I_{z}}\right) y^{\prime}
$$

The maximum bending strength of the casing pipe is

$$
\sigma_{\max }=\frac{M_{\max }}{\mathrm{W}} \leq[\sigma],
$$






FIGURE 7: Curves of water flow rate of rock samples with different fracture distributions.



Figure 8: Changes of water flow rate and radial strain of type I rock sample with declining confining pressures. 


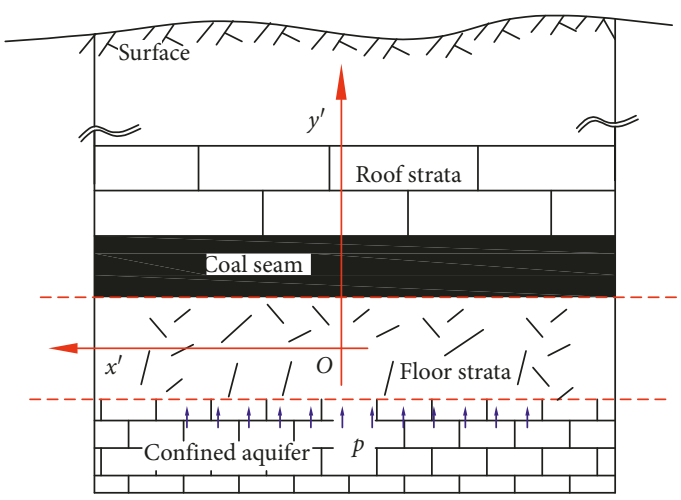

(a)

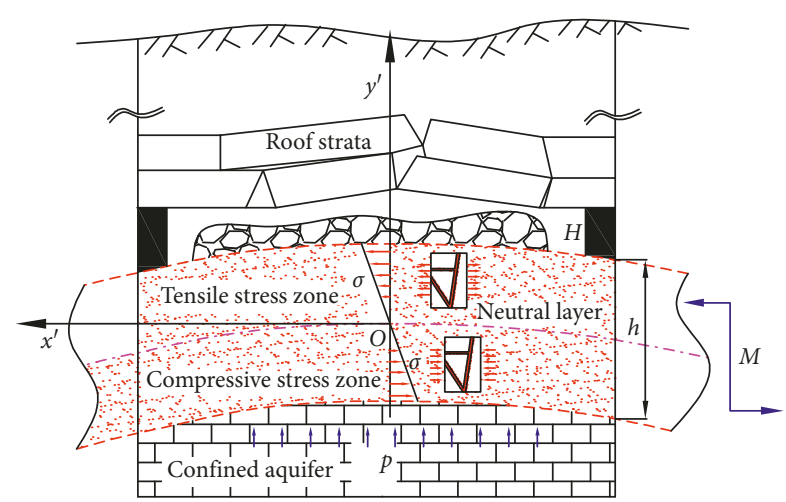

(b)

FIGURE 9: Schematic diagram of rock strata without grouting reinforcement (a) before coal seam mining and (b) after coal seam mining.

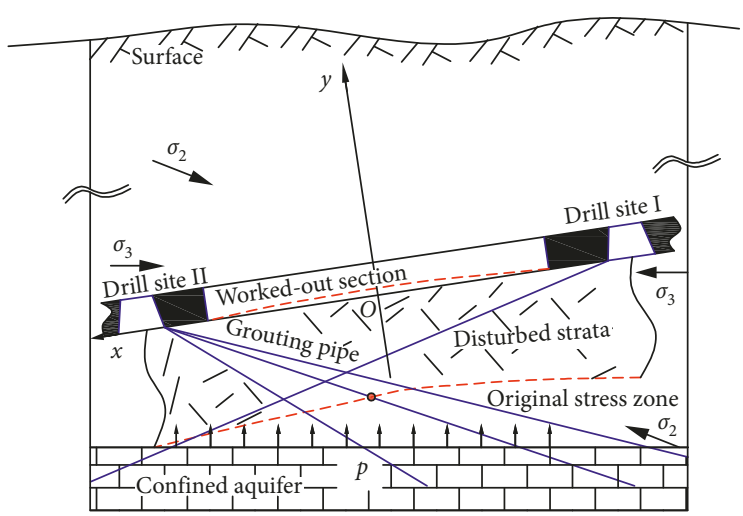

(a)



(b)

Figure 10: Sketch of (a) grouting casing pipes layout in Zhaogu No. 2 coal mine and (b) force analysis of a grouting casing pipe.

where $[\sigma]$ is the bending allowable stress and $W$ is the bending section coefficient of casing pipes.

Thus, as long as the maximum strength of grouting casing pipes is not exceeded, these long grouting casing pipes group can play an important role in controlling floor stratum deformation. The effect of casing pipes in a practical grouting project will be verified by the following numerical calculation.

\section{Numerical Solution of Rock Stratum Deformation before and after Using Grouting Casing Pipes}

5.1. Numerical Model and Basic Parameters. In the first $500 \mathrm{~m}$ of the studied mining area, 12 drill sites and 72 drill holes are designed. The average length of each drill hole is $170 \mathrm{~m}$, and the designed drilling length amounts to $12240 \mathrm{~m}$. The schematic diagrams of the grouting casing layout are shown in Figure 11.

According to the field conditions, the established model is $700 \mathrm{~m}$ long, $180 \mathrm{~m}$ wide, and $210 \mathrm{~m}$ high. Considering the convenience of calculation, the layout of grouting casing pipes is simplified and the numerical model is established as shown in Figure 12.

The stress boundary conditions including water pressure in the numerical calculation is consistent with the boundary conditions of the above test. Referring to the previous relevant studies in this mining area [19], the mechanical parameters of coal seams, roof, and floor strata are appropriately modified for convenience of calculation and listed in Table 1.

Seamless steel pipes with a diameter of $127 \mathrm{~mm}$ are adopted, with elastic modulus of $200 \mathrm{GPa}$, cross-sectional area of $3403 \mathrm{~mm}^{2}$, tensile strength of $245 \mathrm{MPa}$, extrusion strength of $95 \mathrm{MPa}$, and internal compression strength of $98 \mathrm{MPa}$.

5.2. Displacement Analysis of Monitoring Points. Simulate the dynamic excavation process. Each excavation is $50 \mathrm{~m}$ with 2000 steps, and the excavation sequence is shown in Figure 13. Two measuring points, Point I and Point II, are arranged in the floor rock masses, and the distances from coal seam floor to these two points are, respectively, $2 \mathrm{~m}$ and $15 \mathrm{~m}$. 


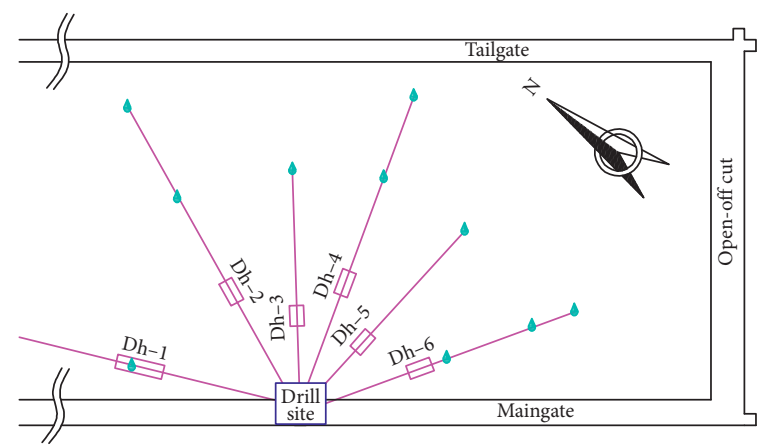

- Water outlet point

(a)

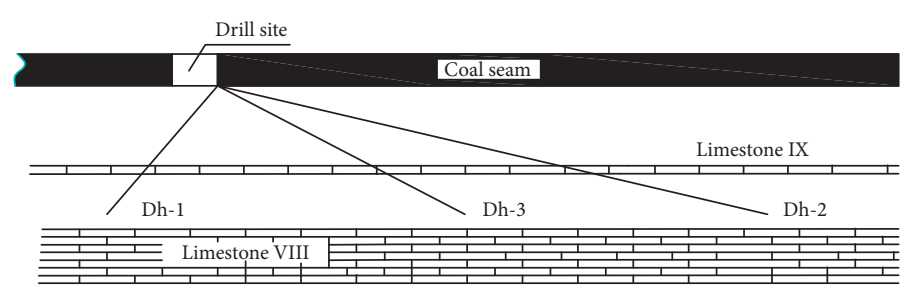

(b)

FIGURE 11: Schematic diagram of (a) grouting casing pipes layout and (b) grouting casing pipes layout section.

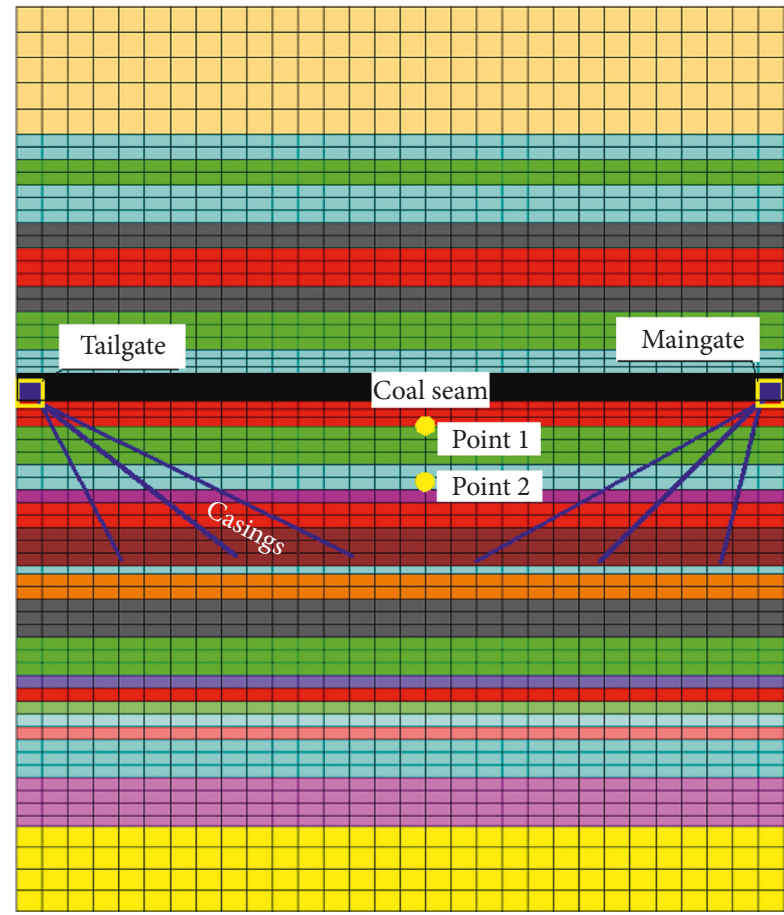

Coal seam

Sandy mudstone

Medium-grained sandstone

Mudstone

Limestone IX

Limestone VIII

Limestone VII

Fine-grained sandstone

Figure 12: Numerical model diagram.

The displacement changes of two monitoring points with and without casing pipes are shown in Figure 14.

As shown in Figure 14, during the first excavation, the monitoring points show that the rock strata near the monitoring points are compressed downward in the first 2000 steps. Then, during the second excavation, the monitoring points show that the rock strata move toward the goaf because the stress above the monitoring points is relieved due to mining activities, and this upward deformation continues in the next several excavations. Specifically speaking, the displacement of point II is less than that of point I, and the displacement of the monitoring points after grouting is smaller than that before grouting, which indicates that grouting casing pipes can effectively prevent deformation of rock masses.

\section{Conclusions}

First, on the microscale level, the laboratory experiment on the pregrouting fractures penetrated by confined water during mining activities was designed and completed, according to in situ stress conditions and rock samples drilled from coal seam floor rock strata. The results show that the response of the radial strain and the water flow rate to mining activities is consistent and positively correlated. More specifically, when the confining pressure is reduced from 25 to $7 \mathrm{MPa}$, the radial strain curve presented an undulation change and the water flow rate increases steadily by $5.7 \%$. When the confining pressure is reduced to less than $7 \mathrm{MPa}$, the water flow rate increases by $10.6 \%$ and the radial strain increases sharply by 16.2 times. At the same time, the Mohr-Coulomb theory is adopted to analyze the failure problem. When stress is greater than $\sigma_{\mathrm{f} 1}$ or $\sigma_{\mathrm{f} 3}$ under the corresponding unidirectional stress state, the interface between cement slurry and the rock mass in the fracture will be destroyed, which is consistent with what is observed during the experiment.

Then, on the macroscale level, the propagation mechanism of grouting cracks due to the deformation of coal seam floor rock strata during mining was analyzed by rock beam theory. Then, a new model of the grouting casing pipes preventing water inrush through controlling deformation of the floor rock strata is proposed, and the deformation governing equation of the casing pipes is deduced theoretically.

At last, the numerical calculation was done to verify the effect of controlling the floor rock strata deformation by the casing pipes group. The displacement of point II (15 $\mathrm{m}$ away from coal seam floor) is less than that of point I ( $2 \mathrm{~m}$ away from the coal seam floor), and the displacement of the 
TABLE 1: Mechanical parameters of rock and floor rock masses.

\begin{tabular}{lccccc}
\hline Rock strata & $\begin{array}{c}\text { Poisson's } \\
\text { ratio }\end{array}$ & $\begin{array}{c}\text { Elastic modulus } \\
(\mathrm{GPa})\end{array}$ & $\begin{array}{c}\text { Internal friction angle } \\
\left({ }^{\circ}\right)\end{array}$ & $\begin{array}{c}\text { Cohesive force } \\
(\mathrm{MPa})\end{array}$ & $\begin{array}{c}\text { Tensile strength } \\
(\mathrm{MPa})\end{array}$ \\
\hline Coal seam & 0.25 & 4.0 & 21 & 1.3 & 1.3 \\
Mudstone & 0.25 & 10.0 & 31 & 3.5 & 1.4 \\
Limestone & 0.30 & 47.0 & 36 & 8.2 & 5.3 \\
Sandy mudstone & 0.27 & 30.0 & 33 & 7.0 & 2.1 \\
Fine-grained sandstone & 0.40 & 17.2 & 35 & 8.5 & 1.6 \\
Medium-grained & 0.26 & 28.5 & 36 & 6.5 & 1.7 \\
sandstone & 0.24 & 23.0 & 33 & 8.2 & 1.5 \\
Coarse-grained sandstone & 0.24 & 26.0 & 39 & 3.6 & 1.4 \\
Roof rock & 0.30 & 50.0 & & \\
Floor rock strata & & &
\end{tabular}

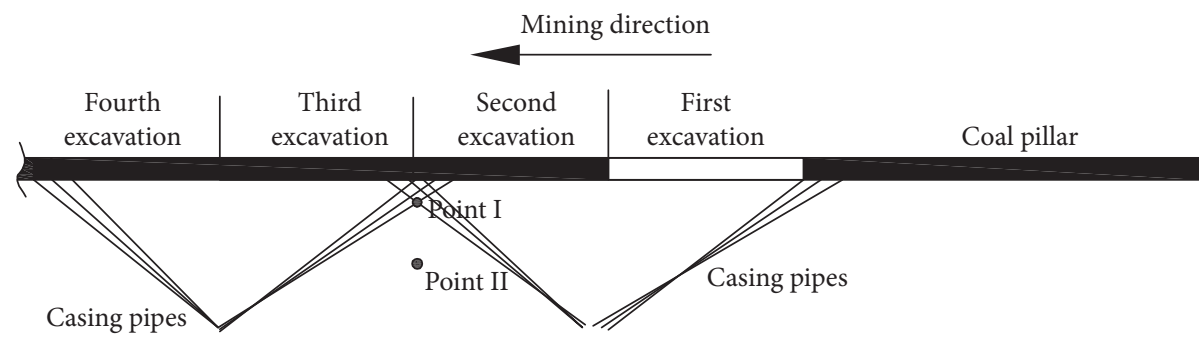

FIGURE 13: Schematic diagram of excavation process.

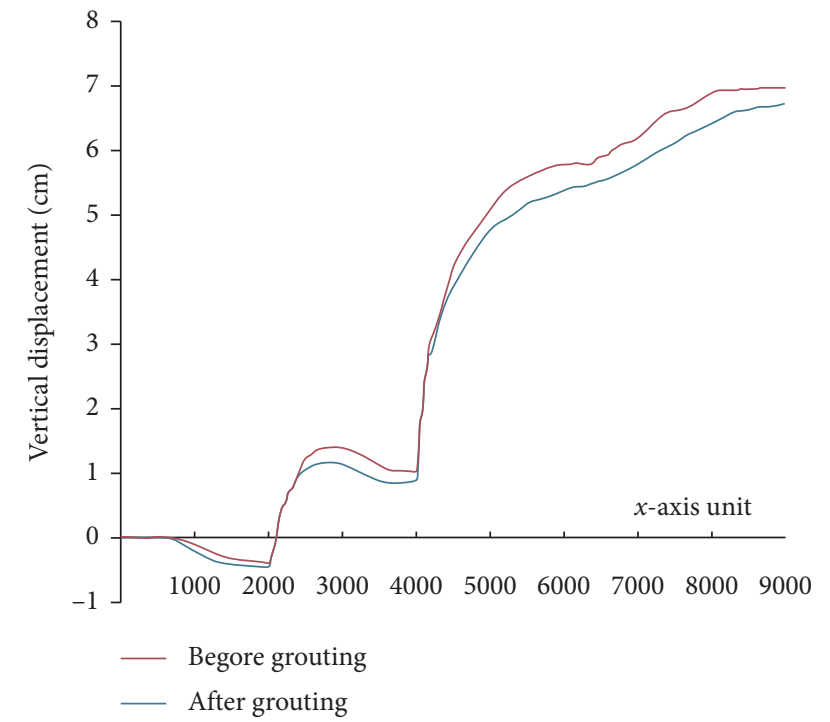

(a)

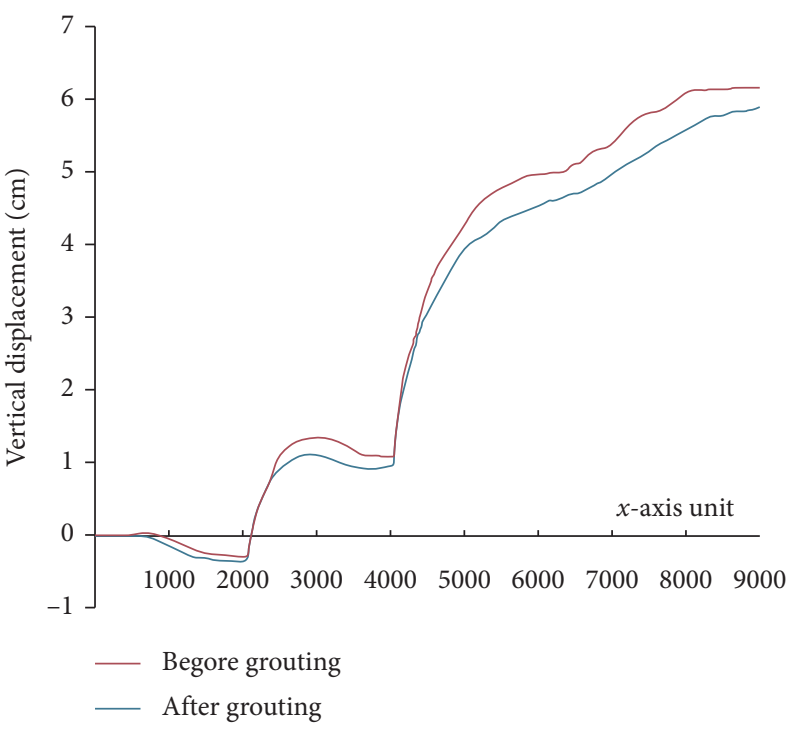

(b)

FIGURE 14: Displacement changes of two monitoring points with and without casing pipes (a) in the place $2 \mathrm{~m}$ away from coal seam floor and (b) in the place $15 \mathrm{~m}$ away from coal seam floor.

monitoring points after grouting is smaller than that before grouting, which indicates that grouting casing pipes can effectively prevent deformation of rock strata. It is practicable to improve grouting technique by optimize the layout of the grouting casing pipes in future.

\section{Discussion}

This study is based on the special geologic conditions and the layout features of many grouting casing pipes arranged in the floor rock masses and focused on explaining the mechanism of water inrush from the pregrouting fractured rock masses, while a new idea of preventing water inrush by considering the bending resistance of long grouting casing pipes is proposed. However, there is still a lot of work to be done, such as increasing the number and the fracture patterns of rock samples, optimizing mechanical model, and carrying out numerical calculation of casing pipes with different angles. The advice, guidance, and contribution of peer experts are really inseparable. 


\section{Data Availability}

The data used to support the findings of this study are included within the article.

\section{Conflicts of Interest}

The author declares that there are no conflicts of interest regarding the publication of this paper.

\section{Acknowledgments}

This work was supported by the National Natural Science Foundation of China (grant no. 51504095), the Fundamental Research Funds for the Central Universities (grant nos. 3142018021, 3142017013, and 3142017083), and the National Key Research and Development Program of China (grant no. 2017YFC0804108). This research was also supported by the Science and Technology Research and Development Project of Langfang in China (grant no. 2017013130). The author is grateful to Jiaozuo Coal Industry Group for providing field testing sites. The author also thanks Professor Yanchun Xu, China University of Mining and Technology (Beijing), for his valuable suggestions.

\section{References}

[1] J. Zhang and B. Shen, "Coal mining under aquifers in China: a case study," International Journal of Rock Mechanics and Mining Sciences, vol. 41, no. 4, pp. 629-639, 2004.

[2] Q. Wu, "Progress, problems and prospects of prevention and control technology of mine water and reutilization in China," Journal of China Coal Society, vol. 39, no. 5, pp. 795-803, 2014.

[3] J. Zhang, "Investigations of water inrushes from aquifers under coal seams," International Journal of Rock Mechanics and Mining Sciences, vol. 42, no. 3, pp. 350-360, 2005.

[4] M. S. Reibiec, "Hydrofracturing of rock as a method of water, mudmand gas inrush hazards in underground coal mining," in Proceedings of 4th IMWA, Belgrade, Yugoslavia, 1991.

[5] O. Sammarco, "Inrush prevention in an underground mine," International Journal of Mine Water, vol. 7, no. 4, pp. 43-52, 1988.

[6] J. Place, A. N. Ghafar, A. Malehmir, A. Draganovic, and S. Larsson, "On using the thin fluid-layer approach at ultrasonic frequencies for characterising grout propagation in an artificial fracture," International Journal of Rock Mechanics and Mining Sciences, vol. 89, pp. 68-74, 2016.

[7] L. Hernqvist, Å. Fransson, G. Gustafson, A. Emmelin, M. Eriksson, and H. Stille, "Analyses of the grouting results for a section of the APSE tunnel at Äspö Hard Rock Laboratory," International Journal of Rock Mechanics and Mining Sciences, vol. 46, no. 3, pp. 439-449, 2009.

[8] A. Zolfaghari, A. Sohrabi Bidar, M. R. Maleki Javan, M. Haftani, and A. Mehinrad, "Evaluation of rock mass improvement due to cement grouting by Q-system at Bakhtiary dam site," International Journal of Rock Mechanics and Mining Sciences, vol. 74, pp. 38-44, 2015.

[9] J. B. Li, Study on the grouting reinforcement working face floor water inrush mechanism and prevention mechanism in the "double high" seam, Ph.D. thesis, China University of Mining \& Technology, Beijing, China, 2016, in Chinese.
[10] X. Z. Yang, J. S. Lei, L. Xia et al., "Study on grouting diffusion radius of exponential fluids," Rock and Soil Mechanics, vol. 26, no. 11, pp. 1803-1806, 2005.

[11] X. M. Chen, Study of the water prevention technology on the working face under great depth and complicated hydrogeological conditions, Ph.D. thesis, China University of Mining \& Technology, Beijing, China, 2013, in Chinese.

[12] J. X. Han, S. C. Li, X. H. Tong, and W. T. Li, "Model study of strength and failure modes of rock mass with persistent cracks," Rock and Soil Mechanics, vol. 32, no. 2, pp. 178-184, 2011, in Chinese.

[13] J. B. Li and Y. C. Xu, "Mechanical model of the collapse column water inrush prevention considering the confined water seepage and its application," Journal of China University of Miniing \& Technology, vol. 45, no. 2, pp. 217-224, 2016.

[14] J. C. Wang and J. B. Li, "Physical model and theoretic criterion of the forecast of water inrush caused by collapse columns," Journal of University of Science and Technology Beijing, vol. 32, no. 10, pp. 1243-1247, 2010.

[15] Z. Q. Yang, Research on Mechanical Mechanism of Ground Stress Effect on Roadway Surrounding Rock Stability and Controlling Technology in Zhaogu Coal Mine, Jiaozuo, Henan Polytechnic University, Henan, China, 2012, in Chinese.

[16] M. G. Qian and P. W. Shi, Mining Pressure and Strata Control, China University of Mining and Technology Press, Xuzhou, China, 2003, in Chinese.

[17] C. N. Srinivasan, "Discussion of "axially loaded concrete-filled steel tubes", Journal of Structural Engineering, vol. 125, pp. 1202-1206, 2014.

[18] A. S. Shakir, Z. W. Guan, and S. W. Jones, "Lateral impact response of the concrete filled steel tube columns with and without CFRP strengthening," Engineering Structures, vol. 116, pp. 148-162, 2016.

[19] M. K. Jia, Y. C. Xu, S. Y. Wei et al., "Prevention and control of water technology through floor grouting reinforcement in high water inrush dangerous mining area," Research Report, Jiaozuo Coal Mining (Group) Xinxiang Energy Co., Ltd. and China University of Mining \& Technology, Beijing, China, 2012, in Chinese. 


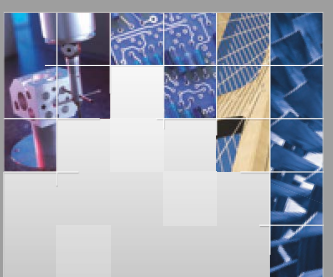

\section{Enfincering}
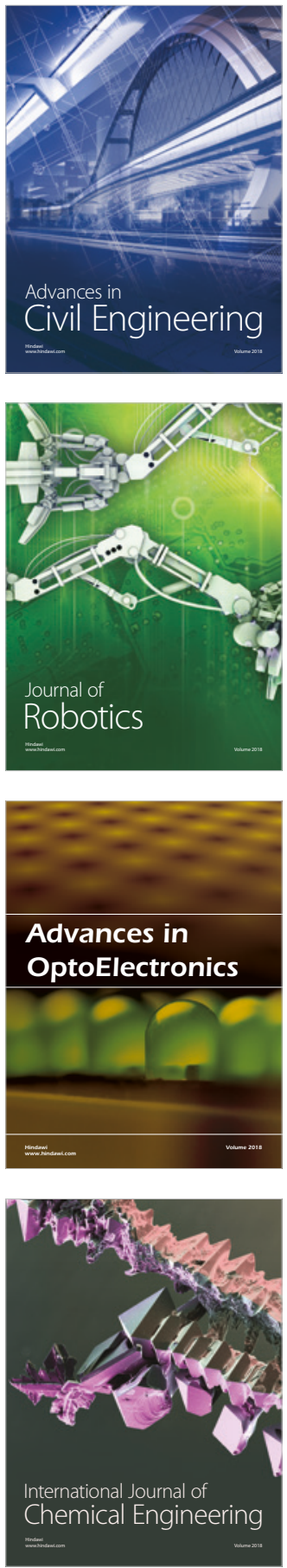

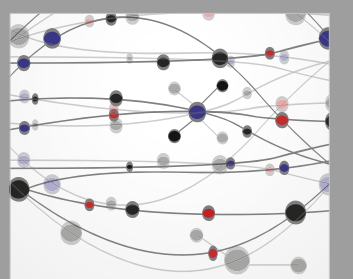

\section{Rotating \\ Machinery}

The Scientific World Journal

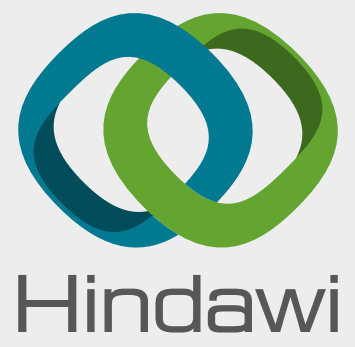

Submit your manuscripts at

www.hindawi.com
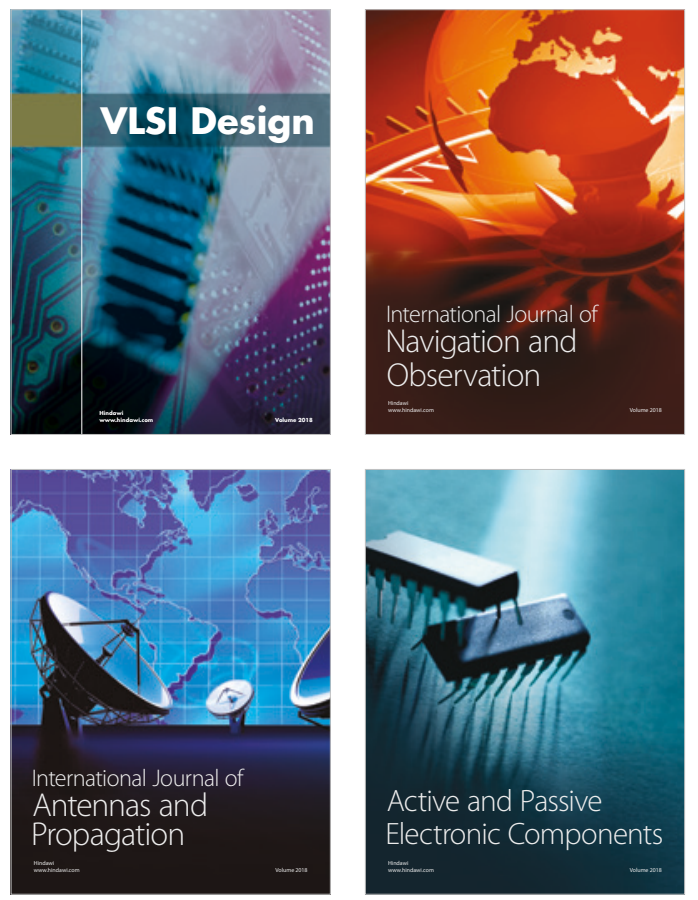


\section{Advances \\ Multimedia}
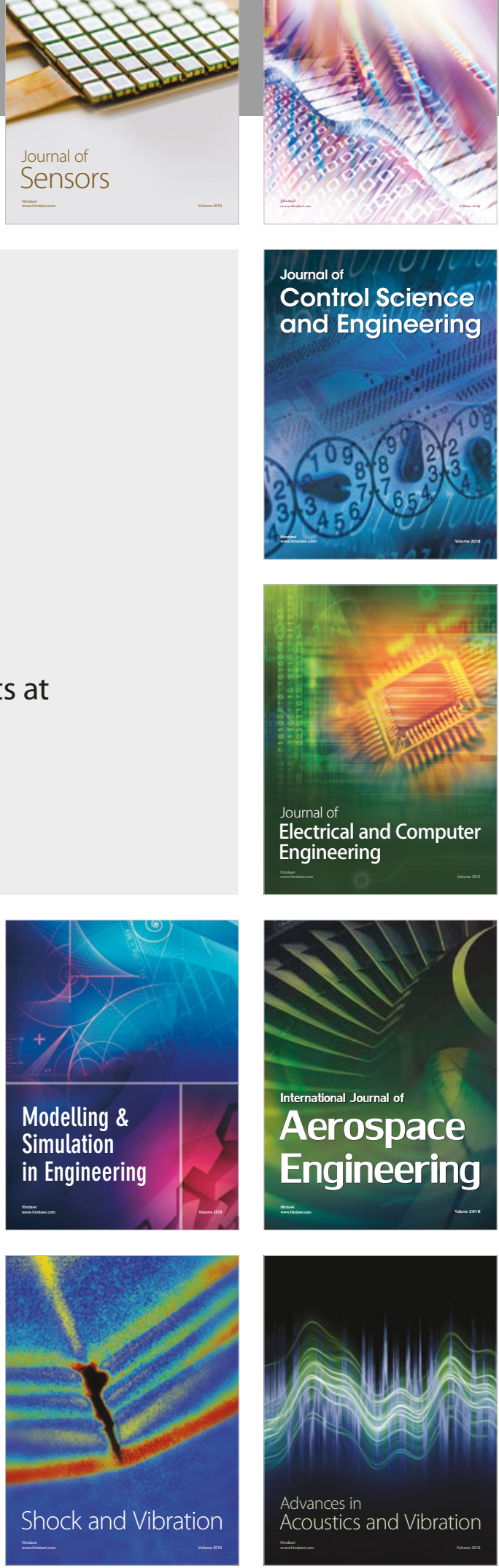